\title{
Empirical Analysis on the Factors Affecting the Location of Household Appliance Chain Store
}

\author{
Congyang Shi
}

School of Economics Shanghai University Shanghai 200444, P.R. China

shicongyang@hotmail.com

Keywords: Household appliances industry; Selection of enterprises location; Factors; Empirical analysis

\begin{abstract}
Since joining the WTO, China's growing openness of the retail sector, and before the end of 2004, China phased out of restrictions on foreign investment in the retail business area, the number of shares and other aspects. Rapid development of home appliance chain enterprises are extremely stunning. How to choose the address targeted retail stores, retail outlets so that every building construction investment marginal revenue can be maximization is one of the most important issue that must be considered by appliance chain enterprises. This paper analyzes the urban location factors for the home appliance chain store location of impact, and use Suning as example to do the empirical analysis, the factors affecting the household electrical appliance enterprise sare traffic store location, population size, wage levels, education levels, real estate and market capacity and activity. Finally some suggestions are given to household electrical appliance enterprises in regional site choosing.
\end{abstract}

\section{影响家电连锁企业门店选址因素的实证分析}

\author{
施从炀 \\ 上海大学 经济学院，中国 上海 200444 \\ shicongyang@ hotmail.com
}

摘要: 我国在加入世贸组织以后不断扩大零售领域的对外开放程度, 并在 2004 年年末之前对 外商投资零售企业逐步取消了在股权、数量和地域等方面的限制。在这样的大背景下，家电 连锁企业发展十分迅猛。如何有针对性地选着零售门店的地址，使每一份建设零售门店建设 投入的边际收益最大化，是家电连锁企业必须考虑的首要问题之一。本文分析了城市区位因 素对于家电连锁企业门店选址的影响, 并以苏宁电器为例做了实证分析, 得出了影响家电企 业门店选址的因素有交通、人口规模、工资水平、教育水平、房地产和市场容量与活跃度等, 最后提出了家电企业在区位选址时的一些建议。

关键字：家电企业；企业选址；影响因素；实证分析

\section{1. 引言}

零售业是竞争性强烈的产业，按照加入世贸组织的承诺，自 2001 年加入世界贸易组织以来， 我国不断扩大零售领域对外开放的程度, 并在 2004 年 12 月 11 日前逐渐取消了外商投资零售 企业在股权、数量和地域等方面的限制。为了强烈的竞争中求得生存, 迎接国际家电连锁巨 头的挑战, 国内家电零售业立不断创新壮大, 迅速发展。作为零售行业的主力军, 家电连锁 企业的发展日新月异，速度之快，让人为之赞叹。

我国家电连锁企业从真正成立到高速发展的十来年里, 家电连锁业成为中国发展最快的行业 之一, 为了不断扩大自身的实力与规模, 国内家电连锁企业都纷纷加快门店扩张、抢占商业 网点, 争夺销售商机。特别是 05 年以后, 各大连锁巨头纷纷加快开店速度, 国美、苏宁零售 
门店的数量连续增加（虽然国美在 2008 年因为其总裁被捕后, 门店数量在 2009 年有所下降, 不过也很快地得到回升)。苏宁和国美的零售门店数量都在 2011 年达到峰值, 在全国范围内 分别有 1684 家和 1079 家店, 后面的几年都维持一个比较稳定的状态。

零售产业门店选择特别重要。业内认为合理的选址对零售企业的成功具有决定性的意义。选 址战略对于家电连锁企业的其他管理活动具有长期性、先行性和全面性的影响。正确合理的 选址策略往往是持久的、不易为竞争对手所模仿的核心的竞争力, 能够帮助企业取得成功。 在零售业，“选址决定赚不赚钱、管理水平决定赚多赚少” 的说法也充分说明了门店选址对于 零售业的重要性。门店选址对家电连锁企业的意义可总结为三点: 第一, 合理的选址策略是 能够帮助家电连锁企业实现规模扩张。家电连锁企业是最具有规模经济效应的行业之一。零 售渠道价值的巩固和增强对规模有着强烈的依赖性, 连锁模式也是家电连锁企业盈利模式得 以实现的基础。因此家电连锁企业有着强烈的规模扩张刺激。而门店选址能够帮助家电连锁 企业实现规模扩张。第二, 门店选址对家电企业的经营具有全面性、长期性的影响。门店选 址是一项长期性投资, 和企业的发展前途紧密相关。一旦门店地址确定, 就需要投入大量的 资金来建设店面。当外部环境发生变化时，它不能像人力资源、资金资源、物质资源等经营 要素可以作相应的调整。同时, 店址也是确定经营目标和制定经营策略的重要依据。不同的 地区的社会环境不同、地理环境不同，在人口状况、交通条件、市政规划方面也有各自的特 点, 它们都在不程度地制约着其区域内的零售门店的顾客来源及特点。第三, 选址不慎, 会 引发公司的经营风险。选址不能盲目夸张, 应注重区域的质量。盲目的选址会引起整个公司 的经营风险。不管销量如何, 供应商在运送商品的过程中都要承担大量的运杂费, 过路费。 门店选址不佳, 或者说交通不方便, 或者其距离与供应商太远, 可能会使供应商放弃与零售 商的合作关系，从而使得零售企业缺失供货来源，这将引发零售企业的经营的风险。

所以如何有针对性地选着零售门店的地址, 使每一份建设零售门店的投入边际收益最大化, 是家电连锁企业必须考虑的首要问题之一。同时, 选址一般包括宏观选址和微观选址。宏观 选址是指选择在什么地区开设门店, 如在上海还是北京; 微观选址是指在选定区域之后, 选 择在该地区的具体什么位置开设门店。本文所研究的选址问题是宏观选址, 主要分析各个城 市的不同因素对家电连锁企业进行门店设址选择的影响。

\section{2. 相关理论回顾}

2.1. 克里斯泰勒中心地理论

德国地理学家瓦尔特 - 克里斯泰勒在三十年代提出来的中心地理论是关于一定地区内城市和 城镇的空间大小、结构分布还有职能的学说。中心理论成立的前提假设条件为: 第一, 研究 区域内的人口密度均匀分布; 第二, 到达该区域内任意方向的交通便捷程度相等; 第三, 生 产者和消费者都是理性的, 即以追求自身的利益最大化为行为目标; 第四, 消费者会选择就 近购物。

在以上假设前提下, 克里斯泰勒认为, 中心地体系的形成由三个不同的原则决定, 分别是: 市场原则、交通原则和行政原则。不同的原则会导致中心地网络呈现不同的网络结构, 而且 中心地和市场区域范围大小的等级顺序有着严格的规定。其中: 市场原则是指商品和服务供 应范围要最大。适用于交通便利、经济发达地区; 交通原则是指按照主、亚、次中心之间最 短距离而定出的中心地体系, 适用于新开发地区。由于各中心之问多存在重要交通线, 而次 中心则处于主、亚中心连接线上; 行政原则, 它要求一个主中心地方能控制六个亚中心地域, 每个亚中心地方又可控制六个次中心地域。它是行政管理的结果，适用于自给自足的地区; 当商品经济发展后，行政原则就会给经济联系带来损害。

2.2. 霍特林的直线市场竞争模式

霍特林假设消费者在空间上均匀分布, 对产品的需求量无限大而且不具有弹性; 产品生产成 本在各个地区都相等, 运输费用在各个地区都相等; 产品按生产价格销售, 其运费由消费者 承担。在这种情况下, 如果市场上只有一家企业, 则其在任何区位设立门店都能占有所有市 
场。第二家企业在区位选择时, 要考虑与第一家企业的竞争, 在尽量靠近第一家企业的地点 布局最为有利 (见图 2-1a)。在需求有弹性的条件下, 产品价格会对销售量产生影响。此时, 两个企业在各自在直线市场的 $1 / 4$ 处设置门店 (见图 2-1b)。

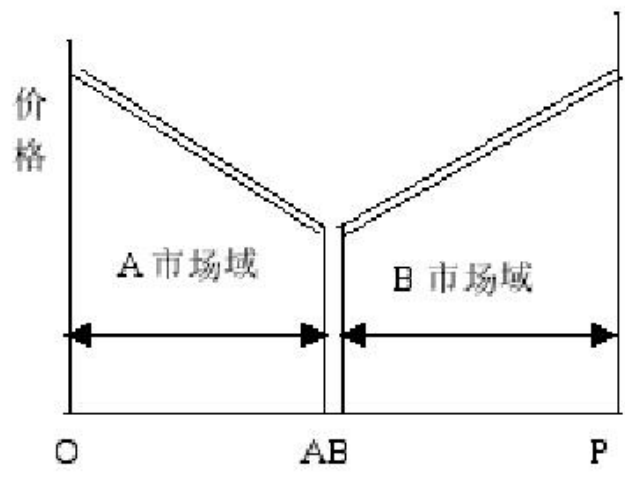

正离



咞离

a. 无限非弹性需求条件下的直线市场竞争

b. 弹性需求条件下的直线市场竞争

\section{图 2-1 霍特林直线市场竞争模式示意图}

\section{3. 影响家电企业门店选址的因素}

\section{1. 因素分析}

连锁家电企业在选择各个城市发展门店数量时要考市场竞争、消费者购买力、市场活跃程度、 营业收入与设址投入的配比等因素。相对应的, 各个地区影响连锁家电企业选址的因素有交 通、人口总数、教育水平、工资水平、房地产及市场容量等等, 这是因素大多是通过影响人 们对家电产品的需求来影响企业的选址决策。

第一, 交通: 城市交通的便利会促进城市零售业的发展, 对于家电企业也不例外。随着这几 年城市轨道交通的发展及普及, 人们在北京上海等特大城市能够方便地在城市中的各个地区 来回。便利的交通能够让消费者有更多的机会接触走进家电零售门店, 所以家电企业也愿意 在交通便利发达的城市多开设门店。不难感知, 在交通发达的城市和交通不发达的城市开设 一家同样的门店，在其他条件相同的情况下，发达城市中的门店拥有更多的客户源。

第二, 人口规模: 人口规模是决定产品总需求量的重要因素。假设每个城市愿意购买某种家 电用品的倾向是一样的, 那么人口总量越多的城市总是对家电产品有着更多的需求。家电企 业在人口总数大的城市有着更多的潜在客户源。人口数量无疑是影响家电企业选址的重要的 因素之一。

第三，工资水平：工资水平代表了人们的实际购买力。消费者只有消费的欲望而没有消费的 能力并不能达成交易。家电产品在全国的零售价几乎都是统一的, 不会因为城市工资水平的 高低而进行差异化定价。这样一来, 高收入人群从大体上讲总是比低收入人群更愿意在家电 产品上支出更多, 尤其是大功率空调、大型彩电、智能冰箱等奢侈品家电在工资水平高的城 市更受欢迎。

第四, 教育水平: 教育水平会从两个方面来影响人们对家电产品的需求。一方面, 教育水平 高的人群普遍薪资水平比较高, 具有更高的购买力, 上文已经说过工资水平的影响, 这里不 再赘述; 另一方面, 接受过高等教育的人更愿意接受新鲜事物, 愿意接受一些新兴的家电产 品。受过高等教育的人相对于未受过高等教育的人而言, 消费观念也更加前卫, 在家电产品 更新换代的时候，更愿意置换已有家电设施。

第五, 房地产: 房地产对家电企业的选址影响主要体现在房屋的成交装修上。人们不管是购 买房子后, 多数情况下都会购置家电产品。就算是购买二手房, 房屋里有相应的配套家电设 施, 新房住也会购买一些别的家电用品或是更换一些家电用品。所以可以认为房屋成交量的 大的城市对家电产品的需求也更多。 
第六，市场容量与活跃度：市场容量是指在不考虑产品价格或供应商的策略的前提下市场在 一定时期内能够吸纳某种产品或劳务的单位数目。所以国际市场容量实际上就相当于需求量。 市场容量越大, 越活跃, 可以认为市场上对家电产品的需求越多, 家电产品潜在的交易量越 大。

3.2. 模型的建立与变量的选择

笔者将如上影响家电企业选择的因素构建了如下多远回归模型:

$Y=\alpha+\beta_{1} X_{1}+\beta_{2} X_{2}+\beta_{3} X_{3}+\beta_{4} X_{4}+\beta_{5} X_{5}+\beta_{6} X_{6}+u$

其中:

$\mathrm{Y}$ 是家电连锁企业在各个城市中的门店数量, 城市中的门店数量越多说明家电企业越愿意在 该城市中开设门店;

$\mathrm{X}_{1}$ 代表城市交通状况。这里选取城市中的地铁总长度作为替代变量, 城市中的地铁长度越长, 地铁覆盖城市面积的范围越广，可以认为城市的交通便利度越好;

$\mathrm{X}_{2}$ 代表人口规模。这里选取城市的年末人口总数为替代变量, 年末人口总数越多, 可以认为 城市的人口规模越大;

$\mathrm{X}_{3}$ 代表城市的平均工资水平。这里选取的数据为城市在岗职工平均工资，在岗职工平均工资 越高, 说明该城市人口的购买力越强;

$\mathrm{X}_{4}$ 代表教育水平。笔者从第六次全国人口普查数据中查找了各个城市的在岗职工总数和受过 高等教育包过大专、本科、研究生及其以上学历）的职工总人数, 用公式:

高学历职工比例 $=\frac{\text { 大专总人数 }+ \text { 本科总人数 }+ \text { 研究生及其以上总人数 }}{\text { 在岗职工总人数 }} \times 100 \%$

计算出接受过高等教育的职工占在岗职工总数的百分比, 以百分点代表各个城市的教育水平; $\mathrm{X}_{5}$ 代表房地产对家电企业选址的影响。这里选择城市年度住宅商品房的销售面积作为替代变 量，因为住房不同于其他商品，各个城市的房价水平差异很大，所以房地产总投资等货币形 式表示的变量不一定能准确反映城市中房屋的数量的成交量, 所以选择了销售面积作为替代 变量;

$X_{6}$ 代表了市场容量和活跃程度。这里选择了各个城市年度社会商品零售总额作为替代变量, 可以认为城市的社会商品零售总额越大, 社会商品零售量越大, 市场容量越大, 交易也更为 活跃;

$\mathrm{u}$ 是误差项，代表地方政策性扶持等因素。

各变量的选择及注释可见表 3-1:

表 3-1 影响家电企业门店选址的变量及其注释

\begin{tabular}{|c|c|c|}
\hline & 变量 & 变量注释 \\
\hline $\mathrm{Y}$ & 门店数量 & $\begin{array}{l}\text { 城市中的门店数量越多说明家电企业越愿意在该城市中开 } \\
\text { 设门店 }\end{array}$ \\
\hline$X_{1}$ & 城市地铁长度 $/ \mathrm{km}$ & $\begin{array}{l}\text { 城市中的地铁长度越长, 地铁覆盖城市面积的范围越广, 可 } \\
\text { 以认为城市的交通便利度越好 }\end{array}$ \\
\hline$X_{2}$ & 年末总人口/万人 & 年末人口总数越多, 可以认为城市的人口规模越大 \\
\hline$X_{3}$ & $\begin{array}{l}\text { 在岗职工平均工 } \\
\text { 资/元 }\end{array}$ & 在岗职工平均工资越高, 说明该城市人口的购买力越强 \\
\hline$X_{4}$ & $\begin{array}{l}\text { 受高等教育水平 } \\
/ \%\end{array}$ & 受高等教育的人口比例越大, 购买家电新产品的意愿越多 \\
\hline$X_{5}$ & $\begin{array}{l}\text { 住宅商品房销售 } \\
\text { 面积/万平方米 }\end{array}$ & $\begin{array}{l}\text { 住宅商品房成交面积越大, 商品房成交量越多, 对家电产品 } \\
\text { 的需求也越多 }\end{array}$ \\
\hline $\mathrm{X}_{6}$ & $\begin{array}{l}\text { 社会商品零售总 } \\
\text { 额/亿元 }\end{array}$ & $\begin{array}{l}\text { 社会商品零售总额越大, 社会商品零售量越大, 市场容量越 } \\
\text { 大, 交易也更为活跃; }\end{array}$ \\
\hline
\end{tabular}




\section{4. 实证分析}

本文选择苏宁电器为研究对象做实证分析。苏宁于 1990 年 12 月在中国南京成立, 当时只是 一家 200 平米的空调专卖店。1999 年 3 月, 苏宁南京新街口旗舰店成功开业, 标志着苏宁电 器从空调专营转型到综合电器全国连锁经营。2004 年 7 月, 苏宁云商集团在深交所中小企业 板成功上市。因为国美集团总裁在 2008 年被捕, 国美电器受到严重的冲击, 苏宁抓住机遇, 在 2009 年以 1170 亿元的营业额和 941 家店面规模成为中国最大的商业流通企业。经过 20 几 年的发展, 苏宁电器已经成为国内连锁家电企业的龙头, 所以对苏宁电器做实证分析具有代 表性意义。

本文选取的数据为横截面数据 (如表 4-1), 以苏宁电器 2013 年末在北京、上海、广州、重 庆等十个重要城市的门店总数作为因变量 $Y$ 的值; 各个城市的地铁长度从百度百科中查得; 年末总人数、在岗职工平均工资、住宅商品房销售面积和社会商品零售总额以国家统计局网 站 2013 年的数据为依据; 受教育水平从第六次人口普查的数据中计算得出，近似代替 2013 年的教育水平。

表 4-1 2013 年十个主要城市中变量的数据

\begin{tabular}{|c|c|c|c|c|c|c|c|}
\hline $\begin{array}{l}\text { 城 市 } \\
\text { 名称 }\end{array}$ & $\begin{array}{l}\text { 门店 } \\
\text { 数量 }\end{array}$ & $\begin{array}{l}\text { 城市地铁 } \\
\text { 长度 } / \mathrm{km}\end{array}$ & $\begin{array}{l}\text { 年末总人 } \\
\text { 口/万人 }\end{array}$ & $\begin{array}{l}\text { 在岗职工平 } \\
\text { 均工资/元 }\end{array}$ & $\begin{array}{l}\text { 受高等教 } \\
\text { 育水平 } / \%\end{array}$ & $\begin{array}{l}\text { 住宅商品房销售 } \\
\text { 面积/万平方米 }\end{array}$ & $\begin{array}{l}\text { 社会商品零 } \\
\text { 售总额/亿元 }\end{array}$ \\
\hline 上海 & 71 & 548 & 1432.34 & 91477 & 35 & 2015.81 & 8052 \\
\hline 北京 & 69 & 513 & 1316. 34 & 93977 & 47 & 1363. 67 & 8375.1 \\
\hline 重庆 & 47 & 202 & 3358. 42 & 51015 & 27 & 4359. 19 & 4599.8 \\
\hline 广州 & 41 & 259.84 & 832.31 & 73678 & 17 & 1398. 47 & 6882.8 \\
\hline 天津 & 37 & 140 & 1003. 97 & 68864 & 32 & 1720.34 & 4470.4 \\
\hline 深圳 & 30 & 178 & 310.47 & 77721 & 17 & 527.16 & 4433.6 \\
\hline 南京 & 28 & 180.5 & 643. 09 & 66222 & 25 & 1143.15 & 3531.7 \\
\hline 成都 & 26 & 65 & 1187.99 & 84724 & 28 & 2555.81 & 3752.9 \\
\hline 武汉 & 20 & 95.6 & 822.05 & 53684 & 26 & 1750.43 & 3916.6 \\
\hline 杭州 & 15 & 66.3 & 706.61 & 64958 & 21 & 968.78 & 3531.2 \\
\hline
\end{tabular}

数据来源：收集整理于苏宁年报、中华人民共和国国家统计局网站及百度百科

用计量软件 stata11. 0 对如上述数据进行回归后, 得到表 $4-2$ 的结果, 其中 $\mathrm{R}^{2}=0.9763$ 。

表 4-2 模型回归结果

\begin{tabular}{lllllll}
\hline $\mathrm{Y}$ & Coef. & Std. Err. & $\mathrm{t}$ & $\mathrm{P}>\mathrm{t}$ & [95\% Conf. & Interval] \\
\hline $\mathrm{X} 1$ & 0.070349 & 0.034695 & 2.03 & 0.136 & -0.04007 & 0.180765 \\
$\mathrm{X} 2$ & 0.004748 & 0.008471 & 0.56 & 0.614 & -0.02221 & 0.031706 \\
$\mathrm{X} 3$ & 0.000142 & 0.000207 & 0.69 & 0.541 & -0.00052 & 0.0008 \\
$\mathrm{X} 4$ & 0.130942 & 0.272953 & 0.48 & 0.664 & -0.73771 & 0.999599 \\
$\mathrm{X} 5$ & 0.00133 & 0.00612 & 0.22 & 0.842 & -0.01815 & 0.020807 \\
X6 & 0.001799 & 0.002757 & 0.65 & 0.561 & -0.00698 & 0.010574 \\
cons & -8.49843 & 14.073 & -0.6 & 0.589 & -53.285 & 36.28813 \\
\hline
\end{tabular}

从回归中结果得到:

$Y=-8.4984+0.070349 X_{1}+0.004748 X_{2}+0.000142 X_{3}+0.130942 X_{4}+0.00133 X_{5}+0.001799 X_{6}$

如所预期的那样，这 6 个因素对于家电企业区位选址决定正向相关。而且模型中 $\mathrm{R} 2=0.9763$, 说明了该模型拟合得很好, 几乎十个样本数据中绝大多数都能能够被解释。常数项为负值 -8. 49843 也可以得到很好的解释。因为只有当一个城市具备上述的某些因素时, 家电企业才 愿意在该城市中开设门店。从回归结果来看, 地铁长度每增加 $1 \mathrm{~km}$, 门店数量增加约 0.07 个 单位; 人口数量每增加 1 万人, 门店数量约增加 0.005 个单位; 人均工资每增加一元，门店 
数量约增加 0.00014 个; 受高等教育程度每上升 1 个百分点, 门店数量约增加 0.131 个; 住 宅商品房销售面积每增加 1 万平方米, 门店数量约增加 0.0013 个; 社会商品总额每增加 1 亿 元, 门店数量约增加 0.0018 个。从 $\mathrm{t}$ 值来看, $\mathrm{X}_{1}$ 的结果最为显著, 可能是因为城市交通便利 不仅是活跃零售市场的因素，也是城市现代化发展程度的一个标志。

\section{5. 结论及建议}

从实证分析中我们可以看出影响家电企业门店选址的主要因素有交通、人口规模、工资水平、 教育水平、房地产和市场容量与活跃度等。像苏宁电器这样的家电巨头将上海、北京等特大 城市作为了其战略重点城市, 虽然苏宁在南京起步, 目前却在上海这样的国际大都市开设了 最多的门店。但是上海北京等特大型城市基本的门店数量基本上已经处于饱和状态。

随着国民经济的发展、人们生活水平的提高, 家电连锁企业应该多关注重庆、成都、长沙、 武汉等位居二线的城市。因为在这些位居二三线的城市中, 人们的生活水平也在不断提高, 可支配收入也在不断增加, 与北京上海等特大城市的发展瓶颈相比, 这些城市更有可能成为 新的销量增长点，家电连锁企业应该抓住机会，抢占先机，争夺市场。

从实证结果中, 可以看出交通的便利程度对家电零售企业的选址影响很大, 交通越便捷的城 市, 家电企业越愿意在其中开设更多的门店。在进一步进军二三线城市的过程中, 应该着重 了解该城市的交通规划布局，寻找增长潜力大的市场。

值得注意的是, 随着互联网的迅速发展, 网络购物平台层出不穷, 零售企业也面临着前所未 有的冲击。如何利用互联网开展网络营销, 将线下零售门店与线上销售有机地结合起来是家 电零售企业值得认真思考的一个问题。

\section{参考文献}

[1] William J. Reilly, "Methods for the Study of Retail Relationships", Austin: Bureau of Business Research, University of Texas, 1929.

[2] Conceição, O., M. Fontes, and T. Calapez. The commercialisation decisions of research-based spin-off: Targeting the market for technologies, Technovation, Vol. 32(2012), No.1, p. 43-56.

[3] $\mathrm{Xu}, \mathrm{S}$. Transport economies of scale and firm location, Mathematical Social Sciences, Vol. 66(2013), No.3, p. 337-345.

[4] Jiang, G. F., G. L. F. Holburn, and P. W. Beamish. The Impact of Vicarious Experience on Foreign Location Strategy, Journal of International Management, Vol. 20(2014), No.3, p. 345-358.

[5] Colombo, L., and H. Dawid. Strategic location choice under dynamic oligopolistic competition and spillovers [J]. Journal of Economic Dynamics and Control, Vol. 48(2014), No.5, p. 288-307.

[6] Elgar, I., B. Farooq, and E. J. Miller. Simulations of firm location decisions: Replicating office location choices in the Greater Toronto Area, Journal of Choice Modelling, Vol. 17(2015), No.12, p. 39-51.

[7] Nilsson, I. M., and O. A. Smirnov. Measuring the effect of transportation infrastructure on retail firm co-location patterns, Journal of Transport Geography, Vol. 51(2016), No.12, p. 110-118.

[8] Zhang, Y., L. Liang, E. Liu, C. Chen, and D. Atkins. Patient choice analysis and demand prediction for a health care diagnostics company, European Journal of Operational Research, Vol.251 (2016), No.1, p. 198-205.

[9] 孙久文. 区域经济学 (第三版) [M].北京: 首都经济贸易大学出版社, 2014. 
[10]孟蹈.空间变化、结构调整与三线企业的集群创新[J].改革,2013,01:35-40.

[11]种法辉,陈丽华,郝兆伟. 基于集群式供应链环境的企业选址问题研究 [J]. 商业研 究,2015,03:161-169.

[12]周浩,郑越.环境规制对产业转移的影响——来自新建制造业企业选址的证据 [J].南方经 济,2015,04:12-26.

[13]申广军.地区比较优势与企业选址一一新结构经济学的一个微观应用 $[\mathrm{J}]$. 经济与管理研 究,2015,04:104-109.

[14]蒋含明.市场潜能、要素价格扭曲与异质性企业选址一一来自于中国微观企业的经验证据 [J].产业经济研究,2015,04:51-59.

[15]逯宇铎,戴美虹,刘海洋.全要素生产率如何影响我国制造业企业的区位选址决策 $[\mathrm{J}]$.运筹与 管理,2015,05:116-125.

[16]李佩源,王春阳.外资企业选址与企业生产率[J].南方经济,2015,09:66-79.

[17]梁辉,孟祥菁, 叶波. 基础设施投资对落后地区经济发展的影响一以京九铁路为例 $[\mathrm{J}]$. 城 市发展研究,2013,10:106-111.

\section{References}

[1] William J. Reilly, "Methods for the Study of Retail Relationships", Austin: Bureau of Business Research, University of Texas, 1929.

[2] Conceição, O., M. Fontes, and T. Calapez. The commercialisation decisions of research-based spin-off: Targeting the market for technologies, Technovation, Vol. 32(2012), No.1, p. 43-56.

[3] $\mathrm{Xu}, \mathrm{S}$. Transport economies of scale and firm location, Mathematical Social Sciences, Vol. 66(2013), No.3, p. 337-345.

[4] Jiang, G. F., G. L. F. Holburn, and P. W. Beamish. The Impact of Vicarious Experience on Foreign Location Strategy, Journal of International Management, Vol. 20(2014), No.3, p. 345-358.

[5] Colombo, L., and H. Dawid. Strategic location choice under dynamic oligopolistic competition and spillovers [J]. Journal of Economic Dynamics and Control, Vol. 48(2014), No.5, p. 288-307.

[6] Elgar, I., B. Farooq, and E. J. Miller. Simulations of firm location decisions: Replicating office location choices in the Greater Toronto Area, Journal of Choice Modelling, Vol. 17(2015), No.12, p. 39-51.

[7] Nilsson, I. M., and O. A. Smirnov. Measuring the effect of transportation infrastructure on retail firm co-location patterns, Journal of Transport Geography, Vol. 51(2016), No.12, p. 110-118.

[8] Zhang, Y., L. Liang, E. Liu, C. Chen, and D. Atkins. Patient choice analysis and demand prediction for a health care diagnostics company, European Journal of Operational Research, Vol. 251(2016), No.1, p. 198-205.

[9] Sun Jiu-wen. Regional Economics (Edition 3) [M]. Beijing: Capital University of Economics and Business Press, 2014.

[10]Meng Tao: "The spatial change, structural adjustment and cluster innovation of the enterprises in the third line areas" [J] Reform, (2013), No.1, p.35-40 (in Chinese)

[11]Li Pei-yuan, Wang Chun-yang: "Location Choice of Foreign Firms and Their Productivity", [J] South China Journal of Economics, No.9, p.66-79 (in Chinese) 
[12]Zhou Hao, Yu Zhuang-xiong, Yang Zheng: "The impact of environmental regulation on industry transfer: Evidence from new manufacturing location" [J] South China Journal of Economics, (2015),No.4, p.12-26 (in Chinese)

[13]Sheng Guang-jun: "Regional competitive advantages and location decision-A micro-level application of new structural economics" [J] Research on Economics and Management, (2015), No.4, p.104-109 (in Chinese)

[14]Jiang Hang-ming: "Heterogerneous, market potential and location choice of manufacturing Firm" [J] Industrial Economics Research, (2015), No.4, p.51-59 (in Chinese)

[15]Lu Yu-duo, Dai Mei-hong, Liu Hai-yang: "How does TFP affect Chinese manufacturing firms' regional location decisions?" [J] Operation Research and Management Science, (2015), No.5, p.116-125 (in Chinese)

[16]Li Pei-yuan, Wang Chun-yang: "Location Choice of Foreign Firms and Their Productivity" [J] South China Journal of Economics, (2015),No.9, p.66-79 (in Chinese)

[17]Liang hui, Meng Xiang-qing, Ye Bo: "Research on the influences of infrastructure Investment to the development of backward region: Based on Jingjiu railway" [J] Urban Studies, (2013), No.10, p.106-111 (in Chinese)

作者简介: 施从炀 (1992 年-), 男, 重庆市璧山区, 主要研究方向: 人口资源与环境经济学, 邮箱: shicongyang@hotmail.com 